\title{
Determination of the Multiaxial Failure Criteria for Alumina Ceramics under Tension-Torsion Test
}

\author{
S. Nohut ${ }^{\mathrm{a}, \mathrm{c}}$, A. Usbeck ${ }^{\mathrm{b}}$, H. Özcoban ${ }^{\mathrm{a}}$, D. Krause ${ }^{\mathrm{b}}$ \& G. A. Schneider*a \\ ${ }^{a}$ Hamburg University of Technology, Institute of Advanced Ceramics, Denickestr. 15, D-21073 \\ Hamburg, Germany \\ ${ }^{\mathrm{b}}$ Hamburg University of Technology, Institute for Product Development and Mechanical Engineering \\ Design, Denickestr. 17, D-21073 Hamburg, Germany \\ ${ }^{\mathrm{c}}$ Zirve University, Faculty of Engineering, Kizilhisar Kampusu, 27260, Gaziantep, Turkey
}

$\begin{array}{lll}\text { Corresponding author* } & & \text { : Gerold A. Schneider } \\ & \text { Tel } & :+49-(0) 40428783037 \\ & \text { Fax } & :+49-(0) 40428782647 \\ & \text { E-Mail } & : \text { g.schneider@ tu-harburg.de }\end{array}$

\begin{abstract}
Failure probability of ceramic components in multiaxial stress state can be predicted using the uniaxial test results (e.g. Tension Test, 4-Point-Bending Test) when a suitable multiaxial criterion, which introduces the triaxiality of stress state, is known. In this article, tension-torsion tests were performed with alumina (Alsint 99.7) specimens from a standard manufacturer under two different load cases. Next experimental results were compared with the numerically calculated effective volume and effective surface values according to different multiaxial failure criteria. It was concluded that the specimens failed due to surface flaws and the normal stress criterion is the most appropriate criterion for the strength prediction of alumina ceramics under multiaxial stress state. Furthermore, it was shown that the Weibull modulus does not play a big role for the prediction of strength of alumina ceramics.

Keywords: B. Failure analysis, C. Strength, C. Mechanical Properties, D. $\mathrm{Al}_{2} \mathrm{O}_{3}$, Multiaxial Failure Criteria
\end{abstract}

\section{Introduction}

Since the strength of advanced ceramics depends on the size of the most critical flaw which varies from specimen to specimen, fracture of ceramics is a probabilistic event as a result of randomly distributed flaws in the material. In order to use ceramics as engineering materials, the scatter of strength has to be characterized. The most widely used expression for this characterization is the cumulative distribution function introduced by Weibull ${ }^{1,2}$ in 1939 . The fundamental assumption of the Weibull theory is "weakest link hypotheses", i.e. the specimen fails, if its weakest volume element fails.

The design challenge for the reliable use of ceramic materials in technical applications is the computation of their failure probability ${ }^{3}$ under prescribed boundary and loading conditions. If a suitable multiaxial 
failure criterion, which introduces the triaxiality of the stress field (e.g. effect of shear stresses), is known, the failure probability of ceramic components under multiaxial stress state can be predicted by using the results of uniaxial tests ${ }^{4}$. Under multiaxial stress state, cracks are subjected to Mode-I (crack opening caused by normal stress perpendicular to the crack plane) as well as Mode-II (crack opening by shear stress acting in the crack plane and perpendicular to its leading edge) and Mode-III (crack opening by shear stress acting in the crack plane and parallel with its front) loading, depending on the position and orientation of the crack plane relative to the principal stresses ${ }^{5}$. Therefore the loading of a given flaw has to be expressed in terms of a suitably defined equivalent stress which depends on the orientation of the crack plane in the local stress field.

A variety of criteria has been proposed for the definition of equivalent stress but due to insufficient information about the crack extension mechanism, it is still not clear which of these criteria is the most appropriate one for ceramic materials. Bansal et. al. ${ }^{6}$ conducted 3-point and 4-point bending tests on alumina $\left(96 \% \mathrm{Al}_{2} \mathrm{O}_{3}\right)$ specimens with two different sizes which have an average grain size of $5 \mu \mathrm{m}$. After that, with four different combinations (small 3-point vs. small 4-point, small 3-point vs. large 4-point, small 4-point vs. large 4-point, small 3-point vs. small 4-point) they compared the experimentally measured mean strength ratios with the predicted ones based on effective volume and effective surface calculations. Effective volume and effective surface values were determined in the usual way ${ }^{7,8}$. In all cases, the theoretically calculated mean strength values according to ratio of effective surfaces showed a better agreement with experimental results. For the case (small 4-point vs. large 4-point), they obtained approximately 7\% deviation between the measured and calculated results. Vardar and Finnie ${ }^{9}$ tested three types of brittle materials (granodiorite, limestone and greenstone) with Brazilian test and did predictions based on bending test using normal stress criterion. They reported that the used criterion is not expected to be valid for materials with spherical flaws and anisotropic materials. Three-point bending tests on extruded porcelain cylinder with radius of $5 \mathrm{~mm}$ and $7 \mathrm{~mm}$ were applied by Lamon and Evans ${ }^{10}$ with three different span lengths. They investigated the size effect for internal and surface dominated flaw populations with a non-coplanar energy release rate criterion and showed consistent results between the observed and expected values. They stated that the internal flaw population dominates at large radii and short span lengths whereas the surface flaw population becomes important at small radii and long span lengths. Lamon ${ }^{11}$ predicted the strengths of disks loaded by uniform pressure and three-point bending specimens of alumina from four-point bending failure data using the maximum non-coplanar energy release rate criterion and showed a close agreement between the predicted and experimental strength 
values. The multiaxial loading fracture of $\mathrm{Al}_{2} \mathrm{O}_{3}$ tubes has been examined experimentally for five different loading conditions, uniaxial axial tension, uniaxial hoop tension, axial tension/ internal pressure, axial compression/ internal pressure and pure torsion ${ }^{12,}{ }^{13}$. Comparison with theory showed that the normal stress criterion underestimated the experimental results. They stated that this underestimation may be related to the fact that this criterion neglects important shear effects and they suggested a modification for shear stress effects in order to provide a more accurate description of ceramic brittle fracture for a wider variety of different stress state. Thiemeier et al. ${ }^{14}$ compared the results of four-point bending tests and ring-on-ring tests with aluminium nitride considering the maximum principal stress criterion, the coplanar energy release rate criterion, the maximum hoop stress criterion, the minimum strain energy density, the maximum non-coplanar energy release rate criterion and the empirical criterion of Richard. They predicted the mean strength for ring-on-ring test from four-point bending test data using a throughwall crack model and a semicircular surface crack model. Although in both cases the deviation between predicted and experimental results were significant (up to approximately 11\%), they reported that for the empirical criterion of Richard and the criterion of the maximum non-coplanar energy release rate, the theory and experiment agreed well. The maximum hoop stress criterion provided very good agreement between theory and experiment in case of through-wall crack but significant deviations occurred if the more realistic crack model of a semicircular crack is used. Furthermore, for both crack models, the deviation between the criteria which give the best and worst agreement was approximately $13 \%$. Scheunemann ${ }^{15}$ performed experiments with alumina rings subjected to internal pressure and then predicted numerically the strength of the rings with different sizes according to different multiaxial criteria. He reported that the empirical criterion of Richard with $\alpha_{1}=10$ showed the best agreement which means that a criteria with high shear-sensitivity will generate best results. On the other hand, Ikeda and Igaki ${ }^{16}$ performed four-point bending of plates and concentric-ring-ring loading of disks under hydrostatic pressure with soda-lime glass in order to achieve triaxial stress state and related to the experimental results they concluded that the experimental results agree with the statistical fracture theory for shear insensitive cracks. Furthermore, Brazilian disc test was performed by Brückner-Foit et. al. ${ }^{4,}{ }^{17}$ in order to determine the failure behaviour of natural flaws contained in low- and high strength ceramics namely, Stoneware material, Alumina, HIPSN (ABB material), HIPSN (ESK material), under multiaxial loading and the results of the test series, analysed using multiaxial failure criteria, were compared with the outcome of the other test series (four-point bending test, concentric-ring test, cold-spin disc test). According to the findings of fractographic examination, for the alumina specimens which contain both 
volume and surface flaws, the surface flaws were determined to be critical. On the other hand, failure of both stoneware and silicon nitride materials was triggered by volume flaws. Based on the reference tests performed with four-point bending test or cold-spin disc test, a good agreement was only obtained if a shear-insensitive multiaxiality criterion was used.

The opinion of the researchers here is divided such that while some those say shear stresses have to be taken into account but others claim that shear-insensitive criteria give better agreement between the numerical and experimental results. The main problem with the most of the reports is that mostly uniaxial or biaxial tests were performed where the portion of the shear stresses was not dominant. For example Dortmans and With ${ }^{18}$ predicted the strength for the ball-on-ring and ring-on-ring biaxial tests using the three- and four-point-bending test results of alumina and reported that a combination of tests with varying degree of stress multiaxiality is required for correct determination of the most suitable multiaxial failure criteria. Moreover, in most cases the number of the specimens was small and therefore the results were affected by large scattering. Danzer et al. ${ }^{19}$ showed the effect of number of specimens on the Weibull parameters of a silicon nitride and concluded that for a reasonable determination of Weibull parameters, at least 30 specimens should be tested.

In this article, tension-torsion tests were performed with alumina (Alsint 99.7) specimens. This type of experiment was selected since it is very similar to the loading of a hydraulic piston in an axial piston machine and provides a multiaxial stress state. In this experiment a high percentage of torsion was applied, so that the distinction between the multiaxial failure criteria is expected to be more reliable. Cocks and Searle ${ }^{20}$ investigated the growth of grain-boundary cavities and cracks under multiaxial stress states in the fine grained crystalline materials and they expressed the need for extensive testing of ceramic materials under multiaxial stress states. Approximately 30 specimens were tested under two different load cases and for each case the Weibull parameters $m$ and $\sigma_{0}$ were determined experimentally. In the numerical part, the effective volumes and effective surfaces of the specimens were calculated for both cases with a commercial finite element program ABAQUS and finite element postprocessor STAU ${ }^{21}$ by using different multiaxial failure criteria. In the following, the experimental setup will be first introduced and later the theoretical background of multiaxial statistical analysis will be explained briefly. Finally the experimental and numerical results will be given and compared according to different multiaxial failure criterion.

\section{Experimental Setup}


In this part the experimental setup which was constructed and introduced by Scheunemann ${ }^{22}$ will be described. A picture of the experimental setup is represented in Fig. 1.

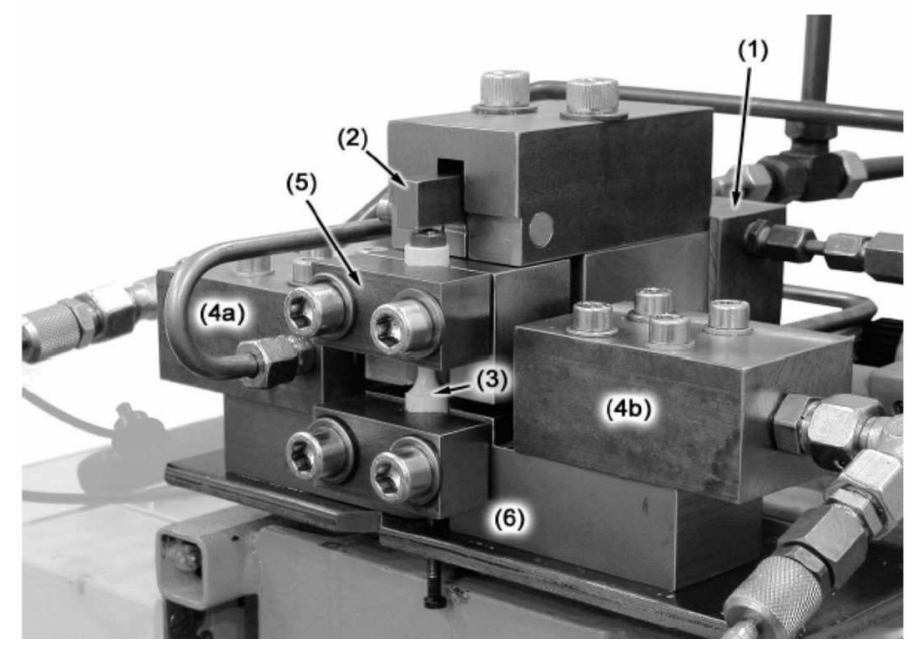

Fig. 1: Picture of the experimental setup ${ }^{22}$, (1) plunger cylinder, (2) connecting arm, (3) sample, (4) plunger cylinders, (5) torsion load launching block, (6) restraint

The lower part of the sample (3) is mounted in the restraint (6) which is a fixed bearing as seen in Fig. 2(a). The upper part is clamped by a torsion load launching block (5) which is a moveable bearing and is able to rotate around the z-axis. The shear force $F_{y}$ is applied with two coaxially fixed plunger cylinders (4a, 4b) as shown in Fig. 2(b). The pressure difference between these two plunger cylinders defines the shear force $F_{y}$ which can be calculated as $F_{y}=\left(\pi d_{p}^{2} / 4\right)\left(p_{1}-p_{2}\right)$ where $d_{p}$ is the diameter of the plunger cylinder and $p_{1,} p_{2}$ are the pressures applied by the plunger cylinders. The discharge of load from specimen to the launching block (5) was applied through a steel ball embedded in the launching block in the first trials of the machine but later a ram was used for which the contact point in the launching block stays as far as possible from the middle level so that the twisting movement of the specimen goes in the minimum lateral drift of the contact point. The compression force $F_{z}$ is applied by a plunger cylinder (1) and through a connecting arm (2) which transmits the force by a ratio of 5:1. The control system of the total experimental setup works through PC with DA/AD converter and a software DASYLAB. The compression force is applied by an operating pressure and the shear force is applied by electrically controlled direction valve. The plunger cylinders consist of a cylinder block with a straight cylinder bore and a cylinder pin (12 mm diameter) as a piston. The sealing on the piston occurs in the gap of the bore where the leak oil is discharged at the end of the bore. Thereby no contact type seal is needed against working pressure since the leak oil is simply prevented by seal ring. With this way, it is possible to construct friction loss plunger cylinders. 
Two types of loads are carried on the specimen as given in Fig. 2(c). A shear force $F_{y}$ acts on the specimen in the $y$-direction by two plunger cylinders $(4 a, 4 b)$ as a function of time as $F_{y}(t)=\left(F_{y}^{\max } / 10 \mathrm{sec}\right) \cdot t$ where $t$ is the time and $F_{y}{ }^{\max }$ is the maximum applied shear force and it is equal to $F_{y}{ }^{\max }=1 \mathrm{kN}$. A compression force $F_{z}$ which is 5 times higher than shear force $F_{z}=5 F_{y}$ deforms the specimen in $z$-direction by the combination of plunger cylinder (1) and connecting arm (2) as a function of time as $F_{z}(t)=\left(5 F_{y}^{\max } / 10 \mathrm{sec}\right) \cdot t$. The compression force is not applied as a point force but as a pressure on the top of the specimen. The effect of the shear force on the specimen appears as a torsion $\tau_{z}=$ $F_{\mathrm{y}} \cdot h_{\mathrm{x}}$ and a bending moment $M_{x}=F_{\mathrm{y}} \cdot h_{\mathrm{z}}$ (see Fig. 3(a)) where $h_{\mathrm{x}}=25.6 \mathrm{~mm}$ and $h_{\mathrm{z}}=20 \mathrm{~mm}$ (see Fig. 2(c)). The main aim for the application of a shear force in this manner, where it creates torsion and bending moment, is to make the portion of the effect of shear stress on the failure of advanced ceramics clear. The shear force, which brings the primary torsion, was applied one-sided and the loading rate was regulated in such a manner that the specimen fails in 1.5 seconds.

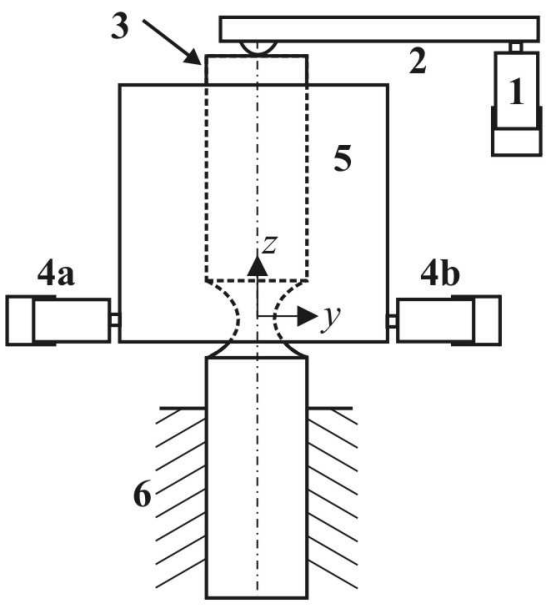

(a)
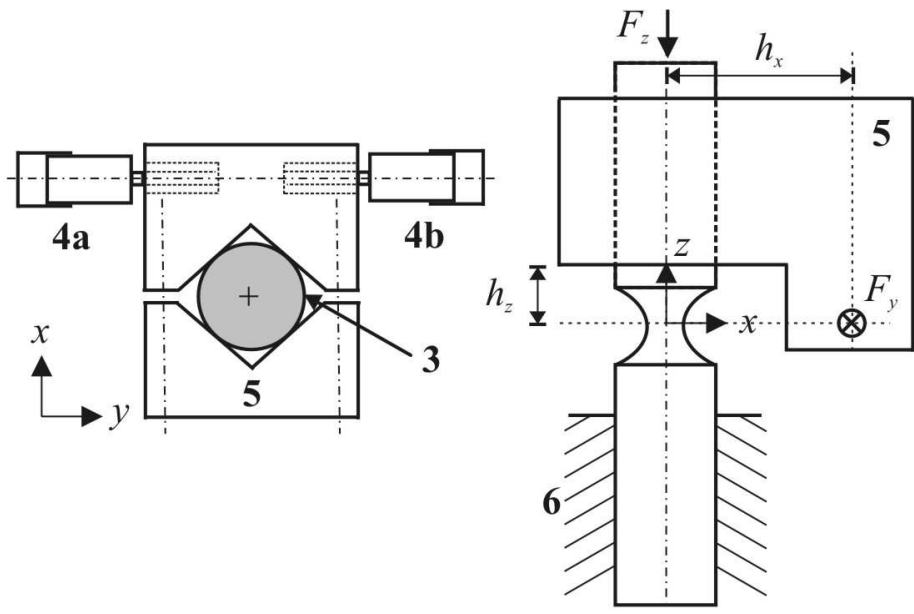

(c)

Fig. 2: (a) Front view of the setup, (b) top view of the setup, (c) side view of the setup and the applied loads on the specimen

Since the upper and lower parts of the specimens are constrained, they show a rigid body motion. Therefore the middle part (notched part) which stays between the upper and lower constraints will be simulated numerically. The dimensions of the investigated section of specimens are given in Fig. 3(b). As stated in the introduction, two load cases will be investigated. In case-1 the specimens will be tested under both shear force $F_{y}$ and compression force $F_{z}$ whereas in case- 2 only with shear force $F_{y}$. In case-1, both $F_{y}$ and $F_{z}$ start to deform the specimen until the failure occurs. As the failure occurs, the maximum principal stress value will be calculated using the measured $F_{y}$ and $F_{z}$ values and will be recorded as the 
strength of the specimen. In case-2, the same experimental procedure will be applied but this time the specimen will be loaded only with $F_{y}$. These experiments are carried out in dry conditions at room temperature.

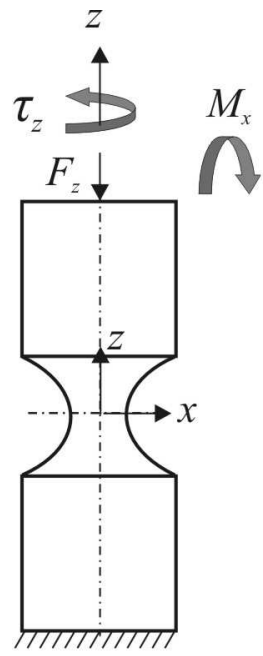

(a)

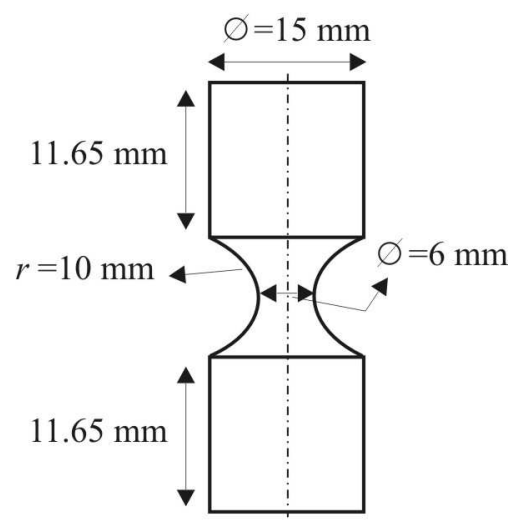

(b)

Fig. 3: (a) Applied loading state on the specimen, (b) The dimensions of the investigated alumina specimen

\section{Multiaxial statistical analysis}

More than 70 years ago, Weibull derived a statistical theory of brittle fracture ${ }^{1,2}$. Since that time, the Weibull distribution function has become the most widely used function in mechanical design of ceramic components. The simplest form of the so-called Weibull function ${ }^{23}$ is given in Eq.(1) for a uniaxial homogeneous tensile stress state.

$$
P_{F, V}(\sigma, V)=1-\exp \left[-\frac{V}{V_{0}}\left(\frac{\sigma}{\sigma_{0}}\right)^{m}\right]
$$

where $P_{F, V}(\sigma, V)$ is the failure probability of a ceramic component due to the volume flaws, $V$ is the volume of the component, $V_{0}$ is the unit volume containing average number of cracks, $\sigma$ is uniaxial applied stress, $m$ is the Weibull modulus which describes the scatter of the strength and $\sigma_{0}$ is the cumulative mean stress at which the failure probability is $63.2 \%$ for a specimen with a volume $V=V_{0}$. In general, the stress distribution within a ceramic component is not constant but takes different values at different positions. Furthermore, in reality the orientation of the cracks in ceramic components is randomly distributed. As a result normal and shear stresses acting in the crack plane cause Mode-I, ModeII and Mode-III loading of the cracks. Therefore, a proper account of the spatial variation in the stress triaxiality (e.g. effect of shear stresses) must be taken by using a multiaxial failure criterion ${ }^{5,24,25}$. 
The orientation of such a crack at point $\bar{r}$ in the global Cartesian coordinate system is given by the direction of the normal of the crack, $\bar{R}_{n}$ relative to three principal axes $\sigma_{1}, \sigma_{2}$ and $\sigma_{3}$ which is described by the Euler angles $\phi, \theta, \psi$ in Fig. 4.

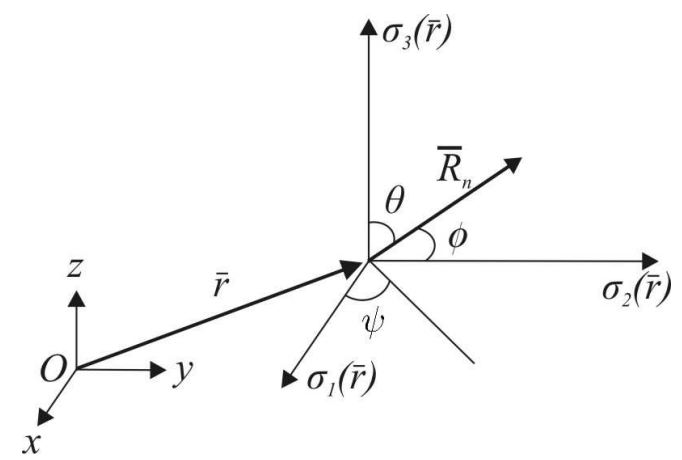

Fig. 4: Representation of a crack in the principal stress coordinate system

Since the orientation of the crack is given in a unit sphere, one of the angles (e.g. $\phi$ ) can be eliminated according to the relationship given below ${ }^{7,26}$ :

$$
\cos ^{2}(\phi)+\cos ^{2}(\theta)+\cos ^{2}(\psi)=1
$$

The stress tensor acting on the area of a penny-shaped crack, whose normal is given by $\bar{R}_{n}$ vector in Fig. 4 , as a function of principal stresses can be written as follows ${ }^{10,27}$

$$
\left[\begin{array}{c}
\sigma_{n} \\
\tau_{I I} \\
\tau_{I I I}
\end{array}\right]=\left[\begin{array}{ccc}
\sin ^{2}(\theta) \cos ^{2}(\psi) & \sin ^{2}(\theta) \sin ^{2}(\psi) & \cos ^{2}(\theta) \\
-\sin (\psi) \cos (\psi) \sin (\theta) & \sin (\psi) \cos (\psi) \sin (\theta) & 0 \\
\cos ^{2}(\psi) \sin (\theta) \cos (\theta) & \sin ^{2}(\psi) \sin (\theta) \cos (\theta) & -\sin (\theta) \cos (\psi)
\end{array}\right]\left[\begin{array}{c}
\sigma_{1}(\bar{r}) \\
\sigma_{2}(\bar{r}) \\
\sigma_{3}(\bar{r})
\end{array}\right]
$$

where $\sigma_{\mathrm{n}}$ is the normal stress and $\tau_{\mathrm{II}}, \tau_{\mathrm{III}}$ are the shear stresses in Mode-II and Mode-III. Failure due to cracks subjected to mixed-mode loading is commonly expressed in terms of an equivalent mode-I stress intensity factor $K_{I, \mathrm{eq}}$ as $^{17}$ :

$$
f\left(K_{I}, K_{I I}, K_{I I I}\right)=f\left(K_{I, e q}, 0,0\right)
$$

Using Eq. (4), an equivalent stress $\sigma_{\text {eq }}$ can be defined which depends on the normal and shear stresses

$$
\sigma_{e q}(x, y, z, \psi, \theta)=\frac{K_{I, e q}}{Y_{I} \sqrt{c}}
$$

where $Y_{\mathrm{I}}$ is the geometric function for mode-I and $c$ is the crack length. The equivalent stress is the uniaxial tensile stress which would have the same damaging action as an applied polyaxial stress state ${ }^{28}$. The proper definition of the equivalent stress does not only depend on the type (position, orientation etc.) of fracture causing crack but also the fracture criterion for the polyaxial stress state. Then the stress $\sigma$ in Eq. (1) should be replaced by the equivalent stress $\sigma_{\mathrm{eq}}$ as 


$$
P_{F, V}\left(\sigma_{e q}, V\right)=1-\exp \left[-\frac{1}{V_{0}} \int_{V} \frac{1}{4 \pi} \int_{0}^{2 \pi} \int_{0}^{\pi}\left(\frac{\sigma_{e q}(x, y, z, \psi, \theta)}{\sigma_{0}}\right)^{m} \sin \theta d \theta d \psi d V\right]
$$

The equivalent stress $\sigma_{\mathrm{eq}}$ can be decomposed as

$$
\sigma_{e q}(x, y, z, \psi, \theta)=\sigma^{*} g(x, y, z, \psi, \theta)
$$

where $\sigma^{*}$ is the reference stress (e.g. maximum principal tensile stress in the component) and $g(x, y, z, \psi, \theta)$ is the geometry function which characterizes the stress distribution relative to the reference stress in the component. Then the effective volume can be calculated by ${ }^{29}$

$$
V_{e f f}=\int_{V} \frac{1}{4 \pi} \int_{0}^{2 \pi \pi} \int_{0}(g(x, y, z, \psi, \theta))^{m} \sin \theta d \theta d \psi d V
$$

The final form of the failure probability function can be formulated as following:

$$
P_{F, V}\left(\sigma^{*}, V_{e f f}\right)=1-\exp \left[-\frac{V_{e f f}}{V_{0}}\left(\frac{\sigma^{*}}{\sigma_{0}}\right)^{m}\right]
$$

Equation (9) introduces the size effect of the ceramic components. For a prescribed failure probability, the strengths $\sigma_{0,1}$ and $\sigma_{0,2}$ for two load cases (case-1 and case-2) with effective volumes $V_{\text {eff, } 1}$ and $V_{\text {eff, }, 2}$ have a relationship as given below ${ }^{30}$

$$
\left(\frac{\sigma_{0,1}}{\sigma_{0,2}}\right)_{\text {experimental }}=\left(\left(\frac{V_{\text {eff }, 2}}{V_{\text {eff }, 1}}\right)^{1 / m}\right)_{\text {numerical }}
$$

In order to calculate the failure probability of a multiaxially stressed ceramic component, $\sigma_{\mathrm{eq}}$ has to be defined. In literature, many different proposals have been reported for the definition of equivalent stress in ceramics but a general agreement on the most appropriate has not been reached. One of the most frequently used criteria is the principle of independent action (PIA) where all principle stresses act independently. In this study, STAU was used for the calculation of effective volumes and effective surfaces and therefore the multiaxial failure criteria will be used which were implemented in STAU. Since PIA criterion does not exist in STAU, the first principle stress criterion (FPS) will be used instead according to the fact that as Danzer et al. ${ }^{5}$ stated, for a material with a Weibull modulus of $m=20$, there is only $4 \%$ deviation between PIA and FPS and this difference between the equivalent stresses is often hidden by the scatter of data. In the following, the considered multiaxial failure criteria in this article will be introduced.

\section{Normal Stress Criterion}


This criterion is based on the assumption that crack extends in the plane perpendicular to the direction of maximum normal tensile stress at the crack-tip regardless of initial plane of the $\operatorname{crack}^{4,1731}$. Depending on this assumption, the equivalent stress is defined as

$$
\sigma_{e q}=\sigma_{n}
$$

Erdogan and $\mathrm{Sih}^{31}$ investigated crack extension in a large Plexiglass (commercial version Plex. II) plates due to its isotropic properties, ease of machining and natural cracks in this material. These plates were subjected to a general plane loading and this criterion was verified theoretically and experimentally with cracked plates under combined tension and shear

\section{First Principle Stress Criterion}

Here it is assumed that the failure is just governed by the maximum principal stress $\sigma_{1}$ as given below ${ }^{32}$.

$$
\sigma_{e q}=\sigma_{1}
$$

\section{$\underline{\text { Von Mises Stress Criterion }}$}

The von Mises stress criterion states that failure occurs when the energy of distortion reaches the energy needed for yield/failure. This criterion is used mostly for ductile materials. The equivalent stress according to this criterion is defined as

$$
\sigma_{e q}=\frac{1}{\sqrt{2}} \sqrt{\left(\sigma_{1}-\sigma_{2}\right)^{2}+\left(\sigma_{2}-\sigma_{3}\right)^{2}+\left(\sigma_{1}-\sigma_{3}\right)^{2}}
$$

\section{The Coplanar Energy Release Rate Criterion}

It is one of the most often used criteria in the literature and it assumes that $K_{\mathrm{IC}}=K_{\mathrm{IIC}}$ and the only criterion which takes $K_{\text {IIIC }}$ into account. In this criterion, it is assumed that the crack extends in the direction of its original plane and the unstable crack propagation occurs when the energy rate reaches a critical value $\mathrm{e}^{33,34}$.

$$
\sigma_{e q}=\sqrt{\sigma_{1}^{2}+\tau_{I I}^{2}\left(\frac{Y_{I I}}{Y_{I}}\right)^{2}+\frac{\tau_{I I I}^{2}}{1-v}\left(\frac{Y_{I I I}}{Y_{I}}\right)^{2}}
$$

where $v$ is the Poisson's ratio, $\sigma_{1}$ is the maximum principal stress, $Y_{\mathrm{I}}, Y_{\mathrm{II}}, Y_{\mathrm{III}}$ are the geometric functions for Mode-I, Mode-II and Mode-III.

The Maximum Non-Coplanar Energy Release Rate Criterion

This criterion assumes that the crack extends in the direction of a plane where the energy release rate reaches its maximum ${ }^{10,35}$. The definition of equivalent stress is: 


$$
\sigma_{e q}=\sqrt[4]{\sigma_{n}^{4}+6 \sigma_{n}^{2} \tau_{I I}^{2}\left(\frac{Y_{I I}}{Y_{I}}\right)^{2}+\tau_{I I}^{4}\left(\frac{Y_{I I}}{Y_{I}}\right)^{4}}
$$

\section{The Maximum Hoop Stress Criterion}

This criterion assumes that the crack grows in the direction where the tangential stress component takes its maximum value at the crack tip ${ }^{31}$. The equivalent stress according to this criterion is written as

$$
\sigma_{e q}=\frac{\sqrt{8}\left[2 \sigma_{n}+6 \sqrt{\sigma_{n}^{2}+8 \tau_{I I}^{2}\left(\frac{Y_{I I}}{Y_{I}}\right)^{2}}\right] \tau_{I I}^{3}\left(\frac{Y_{I I}}{Y_{I}}\right)^{3}}{\left[\sigma_{n}^{2}+12 \tau_{I I}^{2}\left(\frac{Y_{I I}}{Y_{I}}\right)^{2}-\sigma_{n} \sqrt{\sigma_{n}^{2}+8 \tau_{I I}^{2}\left(\frac{Y_{I I}}{Y_{I}}\right)^{2}}\right]^{1.5}}
$$

\section{The Empirical Criterion of Richard}

This criterion is based on fitting a large set of experimental data obtained under multiaxial loading ${ }^{36}$. The equivalent stress is defined as

$$
\sigma_{e q}=\frac{1}{2}\left[\sigma_{n}+\sqrt{\sigma_{n}^{2}+4 \tau_{I I}^{2} \alpha_{1}^{2}\left(\frac{Y_{I I}}{Y_{I}}\right)^{2}}\right]
$$

where

$$
\alpha_{1}=\frac{K_{I C}}{K_{I I C}}
$$

According to experimental studies with alumina ${ }^{37,38}, \alpha_{1}$ gets values between 0.5 and 1.3. Fett and Munz ${ }^{38}$ computed the mixed-mode stress intensity factors for infinitesimally small kink cracks in front of a preexisting crack and compared with the empirical Richard criterion. They concluded that this criterion provides an excellent interpolation for kink crack problems.

By using the finite element program ABAQUS and finite element postprocessor STAU, the effective volumes and effective surfaces of the specimens for both load cases with above introduced mutiaxial failure criteria will be calculated.

\section{Results \& Discussion}

\section{Experimental Results}

In this part the experimental results are presented. In the experimental part of this study, 28 specimens were tested under case-1 loading conditions (shear with compression) and 27 specimens were tested under case-2 loading conditions (shear without compression). The surfaces of the specimens were ground and then polished. Surface roughness measurements were performed for two profiles as given in Fig.5. 
Journal of the European Ceramic Society, 30 (2010) 3339-3349

doi:10.1016/j.jeurceramsoc.2010.08.008
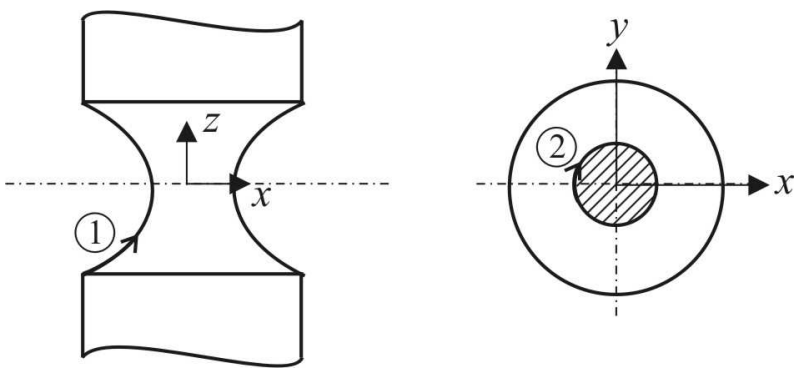

Fig. 5: Paths for the roughness measurements

The measured average roughness was $R_{\mathrm{a}}=0.54 \pm 0.049 \mu \mathrm{m}$ for the first profile and $R_{\mathrm{a}}=0.53 \pm 0.046 \mu \mathrm{m}$ for the second profile. After the experimental tests, the fracture angle of the specimens was measured in order to see the difference in crack-path between the case-1 and case-2. In Fig. 6(a), the bottom part of a broken alumina specimen is shown. The fracture angle $\beta$ is measured by introduction of a fracture plane as shown in Fig. 6(b). The fracture angle was determined on the specimens for both cases.

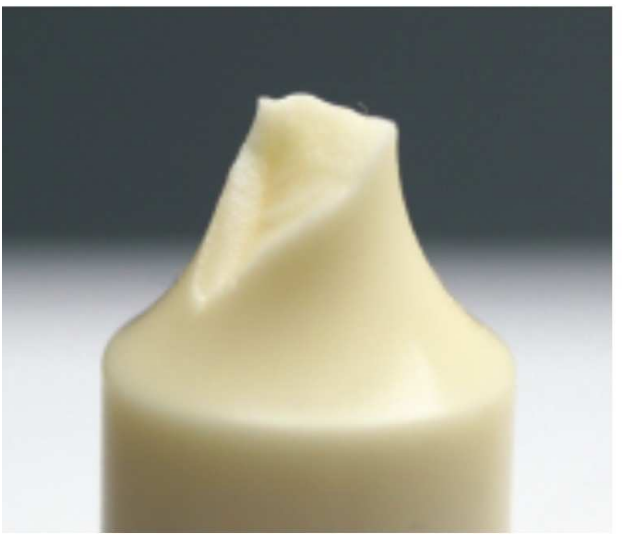

(a)

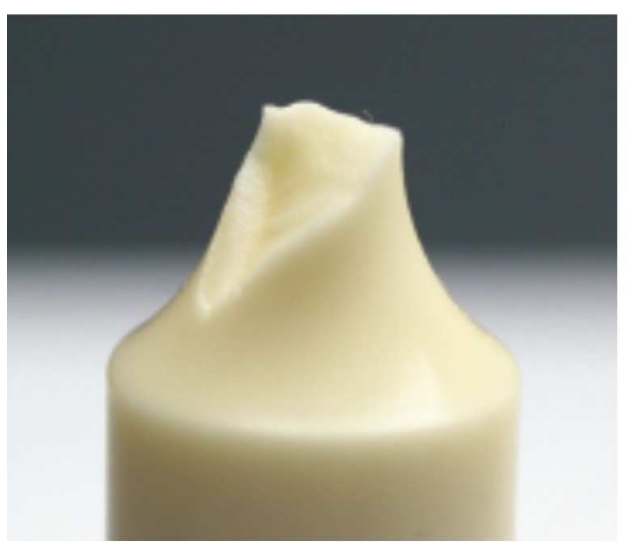

(a)

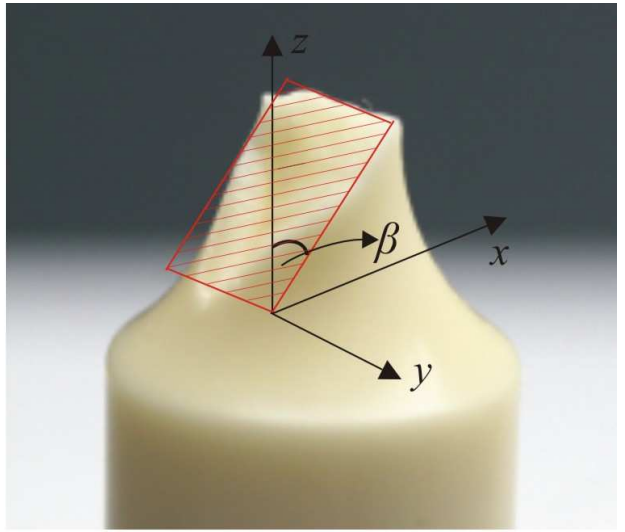

(b)

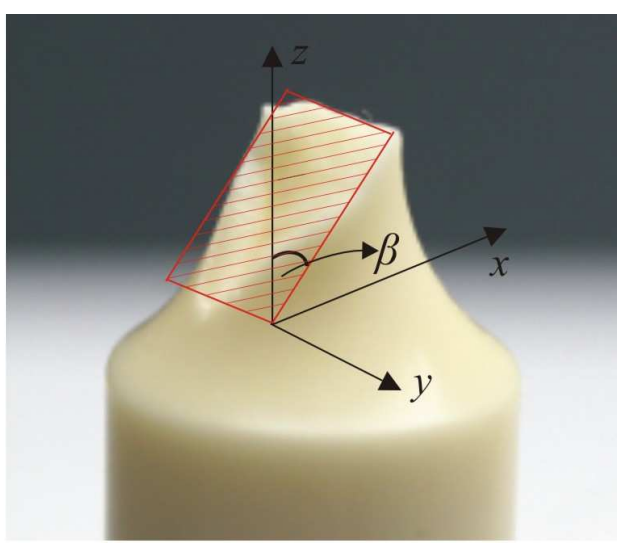

(b)

Fig. 6: (a) Bottom part of a broken specimen, (b) Determination of the fracture angle $\beta$ which is the angle between the coordinate system and the fracture plane

In Fig. 7 some examples of the broken specimens for both cases are shown. Since the fracture surface was rough, it was not possible to measure the accurate fracture angle in most cases. 


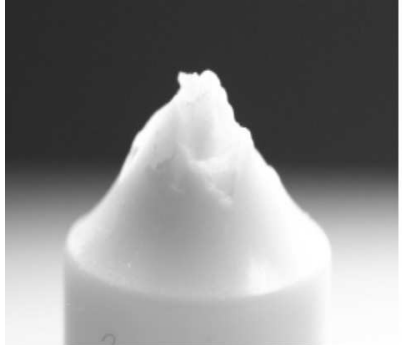

(a)

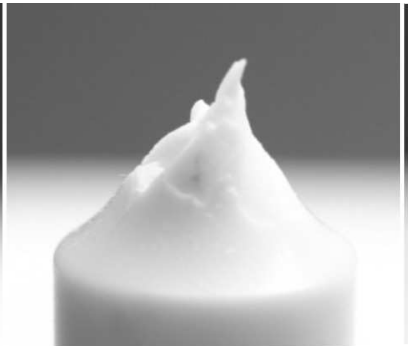

(b)

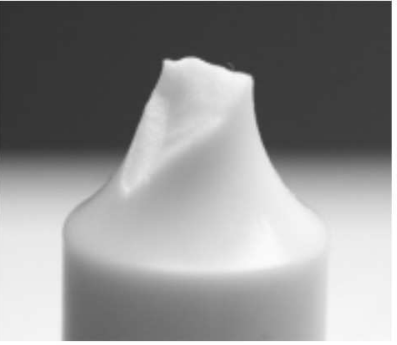

(c)

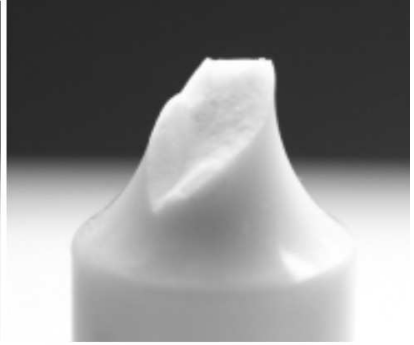

(d)

Fig. 7: Pictures of the broken specimens for ( $\mathrm{a}-\mathrm{b})$ case-1 and $(\mathrm{c}-\mathrm{d})$ case-2

Therefore, an interval is given for the measured fracture angle values. For case-1(with compression), the fracture angle was between $35^{\circ}<\beta_{1}<42^{\circ}$ and for case-2 (without compression) between $44^{\circ}<\beta_{2}<52^{\circ}$. Here it was observed that application of the compression force decreases the fracture angle $\beta$. In order to measure the crack-path orientation more precisely, two specimens were broken partially under case-1 loading conditions and the crack-path was observed by infiltration of tint as given in Fig. 8. The angle of the crack propagation was determined as $41^{\circ}$.
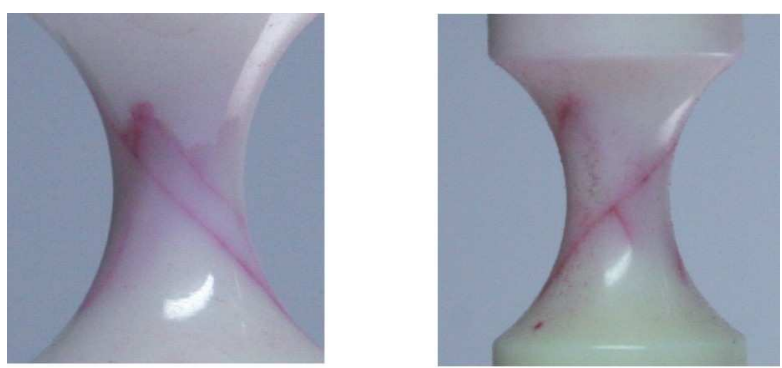

Fig. 8: Crack propagation path

In both loading cases, the maximum shear stresses and maximum principal stresses occur at point-A which is shown in Fig. 9.
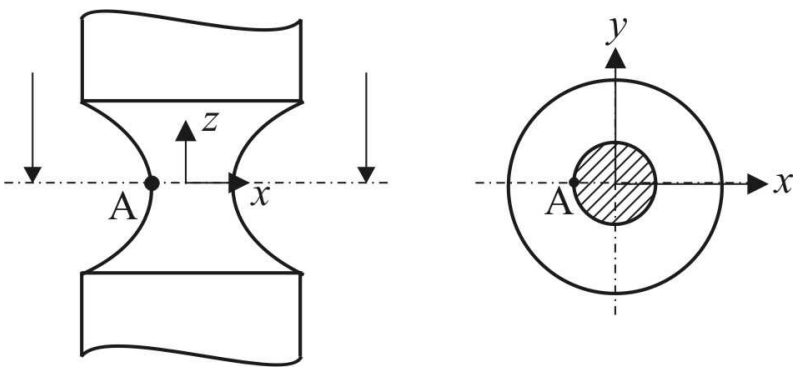

Fig. 9: Representation of the point-A where maximum principal stress occurs

The simple geometry makes it easy to calculate the stress tensor at point-A. The stress tensors at point-A for both cases are given below (coordinate system as given in Fig. 9).

$$
\sigma_{A, 1}=\left[\begin{array}{ccc}
0 & 0 & 0 \\
0 & -15 & 679 \\
0 & 679 & -199
\end{array}\right] \mathrm{MPa} \quad \sigma_{A, 2}=\left[\begin{array}{ccc}
0 & 0 & 0 \\
0 & 0 & 679 \\
0 & 679 & 0
\end{array}\right] \mathrm{MPa}
$$


In case-2 pure shear stresses occur at point-A. Furthermore, in case-1 the ratio of shear stresses to compression stresses is more than 3:1. Therefore, this test stand is suitable in order to investigate the effect of shear stresses on failure of ceramic materials in multiaxial stress state. According to the given stress tensors in Eq.(19), the maximum principal stress values are $\sigma_{1,1}=578 \mathrm{MPa}$ for case-1 and $\sigma_{1,2}=$ $679 \mathrm{MPa}$ for case-2. Using the stress tensors given in Eq. (19), the fracture angle $\beta$ was estimated according to the normal stress criterion as shown in Fig. 10. For case-1 the fracture angle was calculated as $\beta_{1}=41^{\circ}$ and for case -2 as $\beta_{2}=45^{\circ}$.

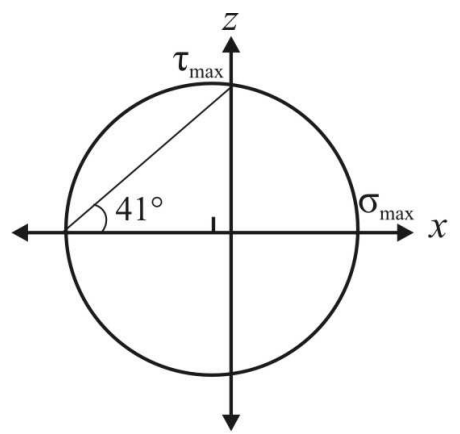

(a)

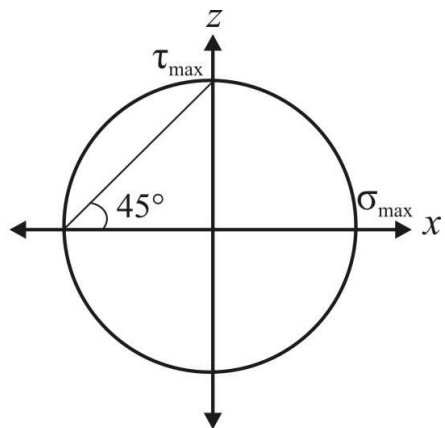

(b)

Fig. 10: Expected fracture angle on $x-z$ plane using the stress tensor given in Eq. (19) according to normal stress criterion for (a) case-1 (b) case- 2

By relating the measured fracture angles with broken and partially broken specimens, it can be concluded that the failure of ceramics under multiaxial stress state can be well described by the normal stress criterion.

The scatter of the strength values for both cases is shown within a Weibull diagram in Fig. 11. The strength values in the Weibull diagram are the maximum principal stresses calculated related to the fracture force.

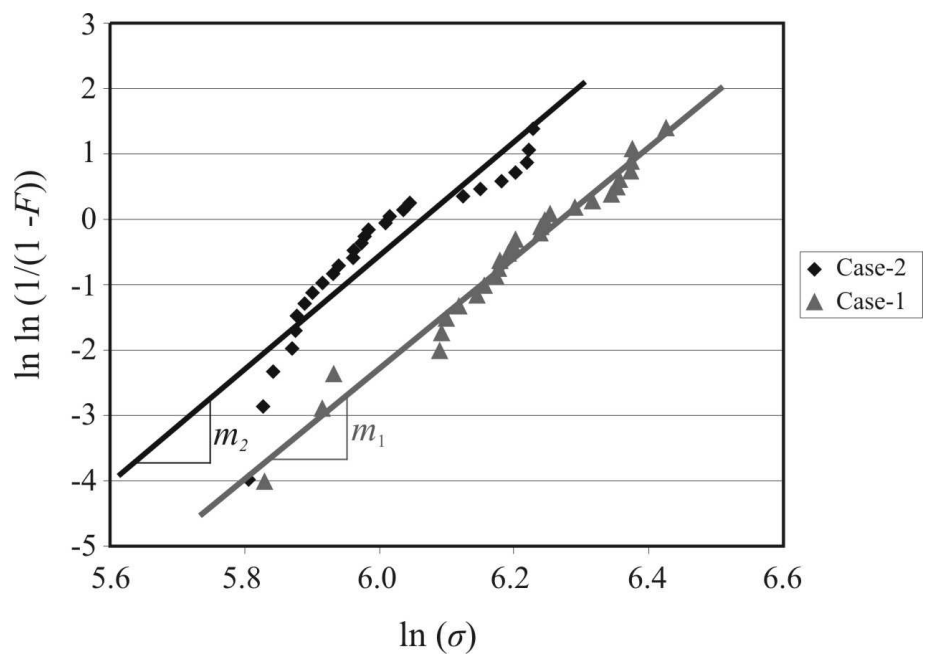

Fig. 11: Representation of scatter of strength by Weibull distribution for both cases (material: AlSint 99.7) 
The Weibull parameters for case- 1 and case- 2 are calculated by Maximum-Likelihood method ${ }^{39}$ and the Weibull modulus $m$ is corrected by a bias factor $b(\mathrm{n})$ according to Thoman et al. ${ }^{40}$

$$
\begin{aligned}
m_{c o r r} & =m b(n) \\
b(n) & =\tanh ^{1.87}\left(\frac{n-3.855}{0.678}\right)^{0.21375}
\end{aligned}
$$

where $m_{\text {corr }}$ is the corrected Weibull modulus, $n$ is the sample size. The experimentally measured Weibull parameters for case- 1 and case- 2 respectively are given below with $90 \%$ confidence interval.

$$
\begin{array}{lll}
m_{1}=7.5[5.9,9.7] & \sigma_{0,1}=524 \mathrm{MPa}[500 \mathrm{MPa}, 548 \mathrm{MPa}] \\
m_{2}=7.3[5.4,8.8] & \sigma_{0,2}=431 \mathrm{MPa}[409 \mathrm{MPa}, 453 \mathrm{MPa}]
\end{array}
$$

The left-handside of Eq. (10) is the equal to

$$
\left(\frac{\sigma_{0,1}}{\sigma_{0,2}}\right)_{\text {experimental }}=1.215
$$

In order to determine the accuracy of the experimental results, the measurement uncertainties of the experimental setup was calculated. The measurement uncertainties of the fracture stress are composed of the uncertainties of (a) the measuring device (applied load on the specimen) and (b) the reproducibility of the mounting (load application).

(a) The load application is measured redundantly with a load cell and two pressure devices. The minimal reproducibility of the pressure device add up to $\Delta \mathrm{p}=0.02 \mathrm{MPa}$. This failure leads to an absolute measurement uncertainty of $\Delta \sigma_{\text {case- } 2}=2,6 \mathrm{MPa}$ and $\Delta \sigma_{\text {case-1 }}=3.1 \mathrm{MPa}$, since the pressure affects both the axial and the radial force.

(b) The uncertainty of load application depends on how the specimen was mounted. Since the stress cannot be measured within the specimen, the following assumptions on load application have been made:

- vertical reproducibility of load application $\Delta \mathrm{v}= \pm 0,5 \mathrm{~mm}$

- horizontal reproducibility of load application $\Delta \mathrm{h}= \pm 0,1 \mathrm{~mm}$

The result of eccentric load application has been computed by FE-methods. The relative stress uncertainties are determined to

- vertically: $\Delta \sigma_{\text {vertically }}=0.7 \% \cdot \sigma$

- horizontally: $\Delta \sigma_{\text {horizontally }}=2.3 \% \cdot \sigma$

Hence the absolute measurement uncertainties for the average stress values add up to: $\Delta \sigma_{\text {case-2 }}=5.6 \mathrm{MPa}$ and $\Delta \sigma_{\text {case-1 }}=18.7 \mathrm{MPa}$. The most significant uncertainty is provoked by the axial load application. The relative measurement error for case- 1 is $3.6 \%$ and for case- 2 is $1.3 \%$. 


\section{Numerical Results}

For the numerical calculations, the Weibull modulus will be taken as $m=7.4$ for both cases. In Fig. 12, the stress distribution obtained by FEM at the middle of the NPT specimens for both cases are displayed.

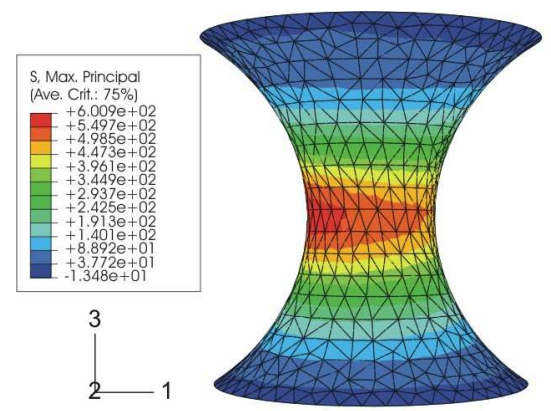

(a)

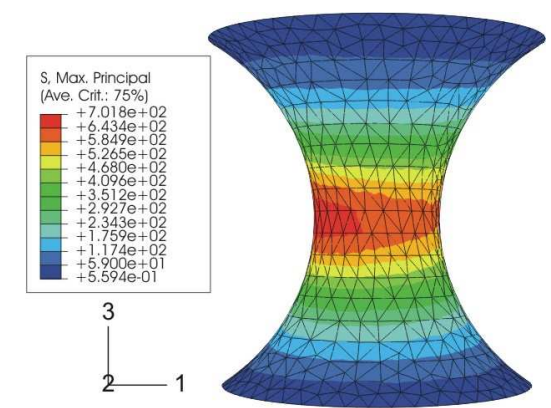

(b)

Fig. 12: Stress distribution obtained with ABAQUS for (a) case-1 and (b) case-2

The maximum principal stress is equal to $601 \mathrm{MPa}$ for case-1 and $702 \mathrm{MPa}$ for case-2. This difference between the values of maximum principal stresses in Fig. 12 shows the effect of the applied compressive force. Furthermore the application of the compressive force changes the stress distribution which results in different effective volume and effective surface values. The total volume of the middle part shown in Fig. 12 is equal to $1067.9 \mathrm{~mm}^{3}$ and the total surface is equal to $917.3 \mathrm{~mm}^{2}$.

The effective volume and effective surface of the specimens were calculated with STAU for different multiaxial failure criteria and the results are given in Table 1.

\begin{tabular}{|c|c|c|c|c|c|c|c|c|}
\hline & Multiaxial Failure Criterion & $V_{\text {eff, } 1}\left[\mathrm{~mm}^{3}\right]$ & $V_{\text {eff, } 2}\left[\mathrm{~mm}^{3}\right]$ & $S_{\text {eff, } 1}\left[\mathrm{~mm}^{2}\right]$ & $S_{\text {eff }, 2}\left[\mathbf{m m}^{2}\right]$ & $\left(V_{\text {eff }, 2} / V_{\text {eff }, 1}\right)^{1 / m}$ & $\left(S_{\mathrm{eff}, 2} / S_{\mathrm{eff}, 1}\right)^{1 / m}$ & $\left(\sigma_{0,1} / \sigma_{0,2}\right)_{\exp }$ \\
\hline $\mathrm{I}$ & Norm. Str. Crit. & 0.304 & 0.407 & 2.847 & 5.864 & 1.040 & 1.103 & 1.216 \\
\hline II & Max. Princ. Str. Crit. & 6.869 & 8.716 & & & 1.033 & & 1.216 \\
\hline III & Empr. Crit. Richard $\left(\alpha_{1}=0.5\right)$ & 0.637 & 0.753 & 5.784 & 6.514 & 1.023 & 1.016 & 1.216 \\
\hline IV & Von Mises Str. Crit. & 16.633 & 15.794 & & & 0.993 & & 1.216 \\
\hline $\mathrm{V}$ & Max. Non-copl. Ene. Rel. Rate & 9.087 & 7.186 & 41.354 & 36.411 & 0.969 & 0.983 & 1.216 \\
\hline VI & Emp. Crit. Richard $\left(\alpha_{t}=1.0\right)$ & 9.892 & 7.178 & 44.701 & 31.688 & 0.958 & 0.955 & 1.216 \\
\hline VII & Copl. En. Rel. Rate & 4.469 & 3.193 & 23.034 & 15.677 & 0.956 & 0.949 & 1.216 \\
\hline VIII & Max. Hoop Str. Crit. & 24.619 & 16.861 & 104.711 & 77.487 & 0.950 & 0.960 & 1.216 \\
\hline
\end{tabular}

Table1: Comparison of numerical and experimental results

It was not possible to calculate the effective surfaces for the maximum principal stress criterion and von Mises criterion with STAU. When the effective volumes for case-1 are compared, the effective volume calculated with the maximum hoop stress criterion is approximately 80 times higher than the effective volume calculated with normal stress criterion. This means, a failure probability calculation using Eq. (9) with the maximum hoop stress criterion would predict the failure probability 80 times higher than with normal stress criterion. This shows the importance of using the most appropriate multiaxial failure 
criterion for designing ceramic components. For the normal stress criterion, the maximum hoop stress

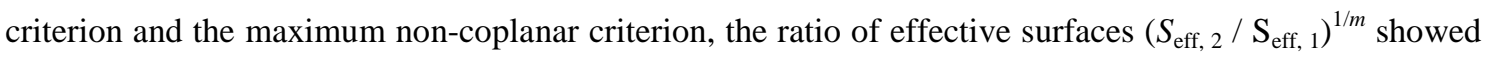

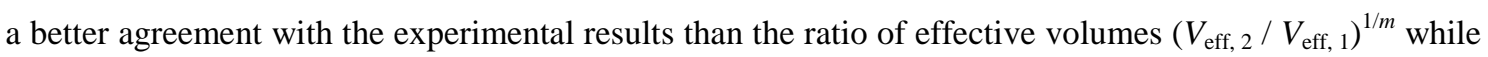
for other criteria, the ratio of effective volumes showed better results. Comparing the numerical results with the experimental ones showed that the normal stress criterion shows the best agreement. Since the ratio of the effective surface gives better results, it can be concluded that specimens failed due to surface flaws. The deviation between the experimentally measured $\sigma_{0,1} / \sigma_{0,2}$ and numerically calculated $\left(S_{\text {eff, } 2} /\right.$ $\left.\mathrm{S}_{\text {eff, } 1}\right)^{1 / m}$ is $9.3 \%$. The representation of the comparison of numerical results with the experimentally determined $\sigma_{0,1} / \sigma_{0,2}$ is given in Fig. 13.

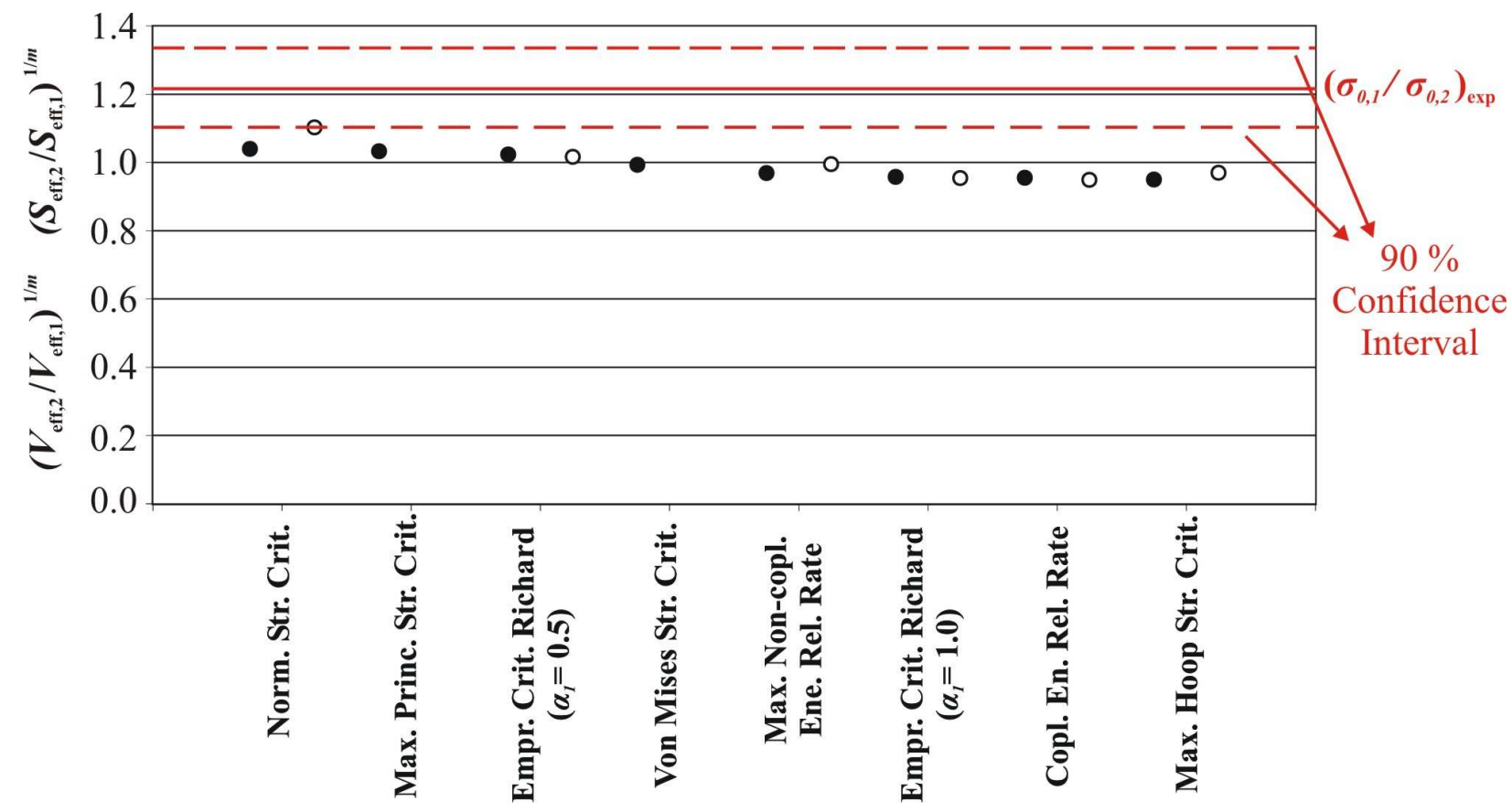

Fig. 13: Comparison of the experimental and numerical results according to effective volume (•) and effective surface (०) computations

The upper and lower dashed lines show the $90 \%$ confidence interval. Furthermore, same numerical calculations are performed with $m=5.4$ and $m=9.7$ (which are the highest and lowest values of the $90 \%$ confidence interval level) and the results with these Weibull modulus values are shown with error bars in Fig. 14. In all cases, calculation with $m=5.4$ showed a better agreement. It can be seen in Fig. 14 that the Weibull modulus does not have a big effect on the numerical prediction. By using Eq. (8), Eq.(10) can be written as given below:

$$
\left(\left(\frac{V_{\text {eff }, 2}}{V_{\text {eff }, 1}}\right)^{1 / m}\right)=\left(\frac{\int_{V} \frac{1}{4 \pi} \int_{0}^{2 \pi} \int_{0}^{\pi}\left(g_{2}(x, y, z, \psi, \theta)\right)^{m} \sin \theta d \theta d \psi d V}{\int \frac{1}{4 \pi} \int_{0}^{2 \pi} \int_{0}^{\pi}\left(g_{1}(x, y, z, \psi, \theta)\right)^{m} \sin \theta d \theta d \psi d V}\right)^{1 / m}
$$


Journal of the European Ceramic Society, 30 (2010) 3339-3349

doi:10.1016/j.jeurceramsoc.2010.08.008

where $g_{1}(x, y, z, \psi, \theta)$ and $g_{2}(x, y, z, \psi, \theta)$ are the geometry functions for case-1 and case-2. The term $1 / m$ in Eq. (22) minimizes the effect of the Weibull modulus.

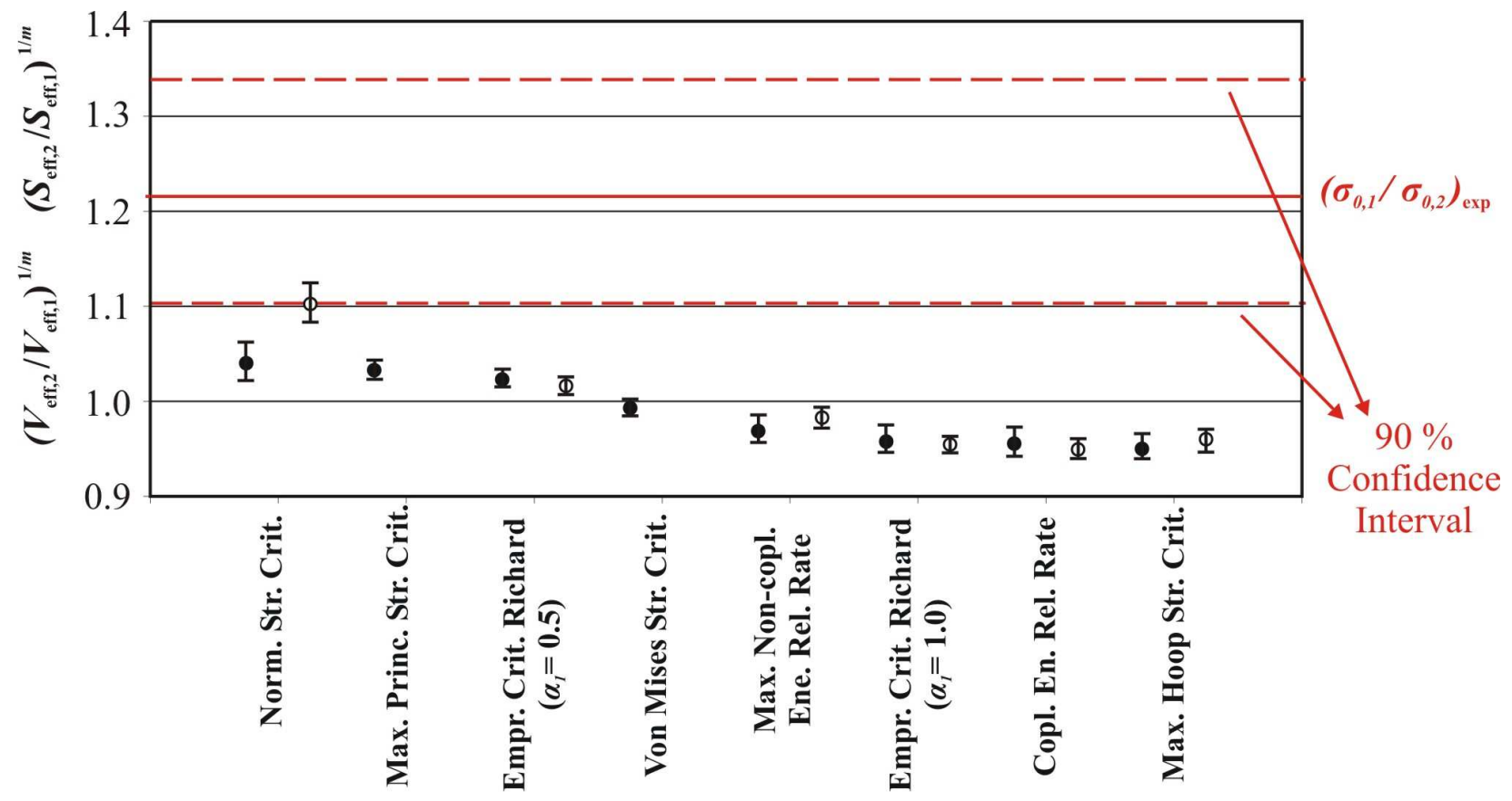

Fig. 14: Comparison of the experimental and numerical results (effective volumes $(\bullet)$, effective surfaces $(\circ)$ ) for different Weibull parameters.

\section{Conclusion}

In this article, tension-torsion tests were performed with alumina specimens under two different load cases. Fracture angles measured with the broken specimens showed that crack propagates perpendicular to the normal stress. Afterwards, the numerically calculated effective volumes and effective surfaces related to different multiaxial failure criteria for two load cases were used in order to identify the most appropriate multiaxial failure. Comparison of the experimental and numerical results showed that normal stress criterion is the most appropriate criterion for the characterization of failure of alumina ceramics under multiaxial stress state. Since the prediction with effective surfaces provided a better agreement, it was concluded that the specimens failed due to surface flaws.

\section{Acknowledgement}

The authors acknowledge support by DFG Graduiertenkollegs "Kunst und Technik". 
Journal of the European Ceramic Society, 30 (2010) 3339-3349

doi:10.1016/j.jeurceramsoc.2010.08.008

\section{References}

1. Weibull, W., A statistical theory of the strength of materials. Ingeniörsvetenskapsakademiens Handlingar, Stockholm ,1939, 151, 1-45

2. Weibull, W., A statistical representation of fatigue failures in solids. Transactions of the Royal of Technology, Stockholm, Sweden, 1949, 27, 5-50

3. Andreasen, J. H., Reliability-based design of ceramics, Materials and Design, 1994, 15 [1], 3-13

4. Brückner-Foit, A., Fett, T., Schirmer, K. S. \& Munz, D., Discrimination of multiaxiality criteria using brittle fracture loci, Journal of the European Ceramic Society, 1996, 16 [11], 1201-1207

5. Danzer, R., Lube, T., Supancic, P. \& Damani, R., Fracture of Ceramics, Advanced Engineering Materials, 2008, 10 [4], 275-298

6. Bansal, G. K., Duckworth, W. H. \& Niezs, D. E., Strength-size distribution in ceramic materials. Investigation of an alumina ceramic. Journal of the American Ceramic Society, 1976, 59 [1112], $472-478$

7. Munz, D. \& Fett, T., Ceramics: mechanical properties, failure behaviour, materials selection. Springer, Berlin, Heidelberg, 1999

8. Wachtman J. B., Mechanical properties of ceramics. John Wiley, New York, 1996

9. Vardar, Ö. \& Finnie, I., An analysis of the Brazilian disk fracture test using the Weibull probabilistic treatment of brittle strength. International Journal of Fracture, 1975, 11 [3], 495508

10. Lamon, J \& Evans, A. G., Statistical analysis of bending strengths for brittle solids: A multiaxial fracture problem, Journal of the American Ceramic Society, 1982, 66 [3], 177-182

11. Lamon, J., Statistical approaches to failure for ceramic reliability assessment. Journal of the American Ceramic Society, 1988, 71 [2], 106-112

12. Petrovic, J. J., Weibull statistical fracture theory for the fracture of ceramics. Metallurgical Transactions, 1987, 18A, 1829-1834

13. Petrovic, J. J. \& Stout, M. G., Multiaxial loading fracture of $\mathrm{Al}_{2} \mathrm{O}_{3}$ tubes: II Weibull theory and analysis. Journal of the American Ceramic Society, 1987, 67 [1], 18-23

14. Thiemeier, T., Brückner-Foit, A. \& Kölker, H. Influence of fracture criterion on the failure prediction of ceramics loaded in biaxial flexure. Journal of the American Ceramic Society, 1991, $74[1], 48-52$ 
Journal of the European Ceramic Society, 30 (2010) 3339-3349

doi:10.1016/j.jeurceramsoc.2010.08.008

15. Scheunemann, P., Discrimination of failure criteria with ceramic rings subjected to internal pressure. Journal of the European Ceramic Society, 2006, 26, 2647-2651

16. Ikeda, K. \& Igaki, H., Effect of Polyaxial stress state on fracture strength of soda-lime glass. Journal of the American Ceramic Society, 1987, 70 [7], 470-474

17. Brückner-Foit, A., Fett, T., Munz, D. \& Schirmer, K. S. Discrimination of Multiaxiality criteria with the Brazilian disc test. Journal of the European Ceramic Society, 1997, 17, 689-696

18. Dortmans, L. \& With D. de., Weakest-link failure prediction for ceramics. IV: Application of mixed-mode fracture criteria for multiaxial loading, Journal of the European Ceramic Society, 1992, 10 [2], 109-114

19. Danzer, R. Lube, T, \& Supancic, P., Monte Carlo simulations of strength distributions of brittle materials- type of distribution, specimen and sample size, Zeitschrift für Materialkunde, 2001, $92[11], 773-783$

20. Cocks, A. C. F. \& Searle, A. A., Cavity growth in ceramic materials under multiaxial stress states, Acta Metallurgica et Materialia, 1990, 38 [12], 2493-2505

21. Brückner-Foit, A., Heger, A., Heiermann, K., Hülsmeier, P., Mahler, A., Mann, A. \& Ziegler, C., STAU 5 - User's Manual - A post processor for a finite element program to calculate the failure probability under thermal schock loading. Institut für Materialforschung II, Karlsruhe, 2005

22. Scheunemann, P., Verfahren und Vorrichtung zur Bestimmung von Werkstoffdaten für die Lebensdauerabschätzung keramischer Bauteile. Dissertation, Cuvilier-Verlag, Göttingen, 2005

23. Danzer, R., Supancic, P., Pascual, J. \& Lube, T. Fracture statistics of ceramics- Weibull statistics and deviations from Weibull statistics. Engineering Fracture Mechanics, 2007, 74, 2919-2932

24. Batdorf, S. B. \& Crose, J. G., A statistical theory for the fracture of brittle structures subjected to nonuniform polyaxial stresses, Journal of the Applied Mechanics, 1974, 41, 267-272

25. Evans, A. G., A general approach for the statistical analysis of multiaxial fracture, Journal of the American Ceramic Society, 1978, 61, 302-308

26. Nohut, S., Reliability of advanced ceramics: Macro- and Mesoscale investigations, Dissertation, Cuvillier-Verlag, Göttingen, 2009

27. Speicher, R.,Experimentelle und theoretische Untersuchungen der Zuverlässigkeit keramischer Ventilplatten in Diesel-Einspritzpumpen. Dissertation, Fortschritt-Berichte VDI, Düsseldorf, 2000 
Journal of the European Ceramic Society, 30 (2010) 3339-3349

doi:10.1016/j.jeurceramsoc.2010.08.008

28. Danzer, R., A general strength distribution function for brittle materials, Journal of the European Ceramic Society, 1992, 10 [6], 461-472

29. Nohut, S. \& Schneider, G. A., Failure probability of ceramic coil springs, Journal of the European Ceramic Society, 2009, 29 [6], 1013-1019

30. Danzer, R., Some notes on the correlation between fracture and defect statistics: Are Weibull statistics valid for very small specimens, , Journal of the European Ceramic Society, 2006, 26 [15], 3043-3049

31. Erdogan, F. \& Sih, G. C., On the crack extension in plates under plane loading and transverse shear. Journal of Basic Engineering, 1963, 85, 519-527

32. Vaughan, H. Crack propagation and the principal-tensile-stress criterion for mixed-mode loading. Engineering Fracture Mechanics, 1998, 59 [3], 393-397

33. Kfouri, A. P. \& Brown, M. W., A fracture criterion for cracks under mixed-mode loading. Fatigue and Fracture of Engineering Materials and Structures, 1995, 18 [9], 959-969

34. Paris, P. C. \& Sih, G. C. Stress analysis of cracks, 1970, ASTM-STP 381, New York, 30-38

35. Hellen, T. K. \& Blackburn, W. S., The calculation of stress intensity factors for combined tensile and shear loading. International Journal of Fracture, 1975, 11 [4], 605-617

36. Richard, H. A., Fulland, M. \& Sander, M., Theoretical crack path prediction. Fatigue and Fracture of Engineering Materials and Structures, 2004, 28 [1], 3-12

37. Petrovic, J. J., Mixed-mode fracture of hot pressed $\mathrm{Si}_{3} \mathrm{~N}_{4}$. International Journal of the American Ceramic Society, 1985, 68 [6], 348-355

38. Fett, T \& Munz, D., Kinked cracks and Richard fracture criterion. International Journal of Fracture, 2002, 115, 69-73

39. Trustrum, K. \& Jayatilaka, A. D. S., On estimating the Weibull modulus for a brittle material. Journal of Materials Science, 1979, 14 [5], 1080-1084

40. Thoman, D. R., Bain, L. J. \& Antle, C. E., Inferences on the parameters of the Weibull distribution. Technometrics, 1969, 11 [3], 445-460 